
Examining Three Roles of Urban "Portals" in their Relationship with "Places" using Social Media Photographs

Xiao Qian

Department of Architecture and Built Environment, University of Nottingham, Nottingham, United Kingdom NG7 2RD

Tim Heath,

Department of Architecture and Built Environment, University of Nottingham, Nottingham, United Kingdom NG7 2RD 


\title{
Examining Three Roles of Urban 'Portals' in their Relationship with 'Places' using Social Media Photographs
}

\begin{abstract}
Portals are the transition spaces between paths and places in an urban environment such as the entrance to a square from a connecting street. This paper aims to explore different forms of portals by considering their relationship with places. In doing so, a people-generated image analysis was adopted for two case studies conducted in popular Chinese recreational venues: Sanlitun Village, Beijing; and Xintiandi, Shanghai. Through an analysis of nearly 53,000 Instagram photographs, three different roles that a portal can fulfil are identified and defined as the 'doorway', the 'showroom', and the 'place'. These typologies are derived from a deeper understanding of urban space through the 'eyes of the users', and this knowledge can in turn influence the design process for the public realm and urban spaces.
\end{abstract}

Keywords: portal; urban space; public realm; Instagram

\section{Introduction}

Urban public spaces are generally thought to consist of two primary typologies: streets and squares (Moughtin, 1992). The portal spaces, first explored by Edward T. White (1999), are often overlooked yet they are critical to the binding of streets and squares into a coherent whole and improving the overall connectivity and legibility of the urban form. After naming streets and squares as "paths" and "places", White (1999) defines the portal as a transition point that provides a first glimpse of the following space while marking a shift from a path to a place or vice versa. Although he presents an illuminating discussion of the concept with adequate consideration of its relationship with both paths and places, he tends to overemphasize the role of the portal as the 'end of a path' and neglects its mission as the 'beginning of a place'.

This paper complements White's study of the urban portal by further examining the relationship between portals and places. In doing so, a people-generated image study 
was adopted to better understand the users' perspective rather than purely a professional view. This approach aims to explore the real attitudes of people toward the use of portals and places in everyday life based on their photographs freely posted and shared on social networks. A comparative case study was therefore conducted in two popular destinations in China with the purpose of stimulating new discussion regarding the nature and role of portals within urban environments. During the research, nearly 53,000 photographs that described how people perceived and became acquainted with the two destinations - Sanlitun Beijing and Xintiandi Shanghai - were downloaded through Instagram's public Application Programming Interface (API). These photographs, accompanied by geographic coordinates and captions, were then analyzed using an innovative combination of image analysis and content analysis. After visualizing and comparing the experiences of people in 'portal' and 'place' spaces, three different roles that a portal can fulfil in its relationship to a place were identified as the 'doorway', the 'showroom', and the 'place'. The findings contribute to an in-depth understanding of portals and places, which not only supports White's theory of urban space but can also promote more informed urban design practice.

\section{Theory: The Portal Space}

The different typologies of urban public spaces discussed in urban design literature can generally be organized into two main types: streets and squares. In essence, streets are linear connecting spaces, and squares are enclosed regular or irregular spaces that enable a range of public activities. These two spatial typologies have been widely accepted and adopted by urban researchers and urban designers in exploring what makes a good urban public realm. White (1999) presents an illuminating discussion of them in his book Path-Portal-Place: Appreciating Public Space in Urban Environment. He names streets and squares as "paths" and "places", which to some extent reflects the 
essential features of these spaces. In addition, he introduces a new concept called the "portal" which is often overlooked yet critical to the binding of paths and places into a coherent whole and deserves more attention from urban practitioners.

The portal is defined by White (1999) as a point-like location where one moves from a path to another path or from a path to a place or vice versa. As such, the portal provides a sense of progression as well as the sense of transition. He identifies the basic forms of portals including archways, gateways, and even short spaces bounded by flanking columns or pillars. These spaces make little sense when considered as an independent entity but are meaningful when they are connected to paths and places as part of urban settings. White (1999) emphasizes this aspect in his book by constantly underlining the integrated whole in which paths, portals and places coexist; for example, he has argued that a portal space should involve both the character of the place and the character of the path in addition to establishing its own character or identity.

Although White was probably the first to clarify the definition of portal space, many other researchers have also investigated the portal experience offered by certain public spaces before him. For example, Moughtin (1992) explores the role of Piazza del Popolo as the main entrance to the city of Rome, and he has argued that as a splendid city portal, this square gives all outside visitors coming from the north a powerful first impression of Rome. Tibbalds $(1992,57)$ refers to the portal experience provided by the “arrival point" such as airport, railway station and bus station. He has particularly emphasized the attractiveness of the arrival point that will not only make the intended destination easy to find but also contribute to the first impression of the destination in visitors' minds. The primary function of these portals, according to Moughtin and Tibbalds, is to mark the beginning of a new journey with the ability to help visitors prepare for upcoming encounters. By characterizing and presenting the subsequent 
experience in a simple but powerful 'preview', these portals can therefore, to some extent, serve as a signboard that conveys essential information about the available offerings and thus gives visitors an overall impression of the whole site.

Indeed, White (1999) has mentioned how to make such a preview in a portal space; for example, he captures the anticipatory tension caused by the framed view to a square from a portal and suggests that the position of the portal in relation to the geometry of the square affects its framed view and thereby causes different arrival experiences. Besides, he proposes setting up additional actions in the portal space, such as opening a gate, climbing or descending steps, and shifting direction, to inform visitors of the full appearance and experience of the square that is being entered. However, during White's (1999) discussion, he tends to overemphasize the spatial integrity and continuity and thus places more focus on the perceptual experience of approaching, arriving at, and passing through the portal space. This reflects his intention to regard portals more as an ultimate destination at the end of a path than as a beginning of a place, which strengthens the spatial relationship between the path and the portal yet neglects the potential effects of the portal on people's perception of the following place that it is connected to. As a result, he considers portals as nothing more than just a way to frame a view of the place.

In order to provide a complement to White's study of portals and have more alternatives to increase visitors' anticipation of getting into the final place, this paper presents an extended discussion of the form of portals. The discussion relies on the premise that the form of a portal depends on the characteristics of the adjacent place, and as such requires careful consideration of the relationship between them. In this research, an approach called people-generated image study was adopted to facilitate this understanding. This approach combines the empirical observation of the researcher with 
a quantitative measurement of people's responses in different portals and places by collecting and analyzing their photographs shared on social media platforms.

\section{Method: People-generated Image Study using Social Media Photographs}

White (1999) conducts his study with his empirical knowledge of urban public spaces similar to other researchers including Moughtin (1992) and Tibbalds (1992). This raises a critical question as to how a typical person, rather than a trained professional, perceives the portal and understands its relationship with place? A 'people-generated image study', which means analyzing the mental image of the physical world in an ordinary person's head, was adopted to address this question. The method is a common approach to the understanding of people's attitudes and behaviors toward urban environments. Its practice can be traced back to Kevin Lynch's work on the perceptual forms of urban space in the 1950s (Lynch, 1960). He interviewed local citizens and trained them to pictorialize their perceptual experience of urban space in a sketch map; however, Lynch (1960) also acknowledged that he had imposed strict controls over the whole project in order to obtain precise results, which to some extent influenced the performance of participants and thus undermined the quality of the data received from them.

Since the 1970s, the increased accessibility of photography has enabled researchers to get closer to the real image stored in an individual's mind through an image taken with the camera. The photograph not only provides a visual expression that can be recognized and understood more immediately than any other form of representation such as the sketch map, but also conveys the personal feelings that are often hard to explain using verbal techniques such as the interview. This led to a new research technique which is commonly known as 'visitor-employed photography' 
(Mackay and Couldwell, 2004; Jacobsen, 2007; Dorwart, Moore and Leung, 2009) or 'volunteer-employed photography' (Garrod, 2007). These are methods in which participants are required to take photographs with a camera to express their perceptions in a given environment, which can yield hundreds or even thousands of photographs for a case study. However, the researcher has to identify each and every image to group photographs of the same scene together. By analyzing the scenes and investigating their relationships, the researcher can then begin to understand how participants have seem and perceived the environment.

Since the early 2000s, the rapid development of smartphones and social networks has made tremendous amounts of people-generated image data available and thus facilitated the study of geographical, behavioral and socio-cultural patterns of people in urban environments (Hochman and Manovich, 2013; Ciuccarelli, Lupi and Simeone, 2014). People are increasingly sharing photographs of everyday lives on social media platforms, and thus they can contribute millions or even billions of data files to researchers' efforts in increasing sample size and in turn reducing selection bias. Such a large number of photographs, however, cannot be manually evaluated one by one as could be done in previous studies. Many research projects have attempted to resolve the issue by developing new methods for more reliable quantitative analysis; but they have tended to focus on only one aspect, such as the geographic clustering (Kennedy et al., 2007; Crandall et al., 2009; Cranshaw et al., 2012; Psyllidis et al., 2015; Encalada et al., 2017), the temporal trends (Hochman and Schwartz, 2012; Hochman and Manovich, 2013; Schwartz and Hochman, 2014; Xia et al., 2014), the attached text (Ahern et al., 2007; Sigurbjörnsson et al., 2008; Deng et al., 2009; Xia et al., 2014) and the visual features (Hochman and Schwartz, 2012; Ushizima et al., 2012; Hochman and Manovich, 2013). As with other recent studies (Zhou et al., 2014; Guerrero et al., 2016), 
in order to continue the effort to combine these techniques together to enable a fuller understanding of urban life and the urban environment, this research attempts to develop a new framework for the comprehensive analysis of massive social media photographs.

The primary aim of the people-generated image study conducted in this research is to visualize and interpret the urban experience represented by social media photographs, which is in line with the research purpose of exploring portal-place connection for a better perceptual experience. As such, a three-stage analytical procedure was designed involving division, categorization and visualization. Division refers to the partition of experience into different aspects corresponding to the different subjects of the photographs. The photographs can then be categorized by being organized into groups according to their subject matter. The size of each group represents the proportion of the corresponding aspect in the whole experience. The researcher can thus define the main aspects of the experience by measuring the size of each group and further investigate each aspect by visualizing all related photographs in a specific order.

To be more specific, the first 'division' is an initial assessment of what people have experienced. It is conducted from the perspective that the experience is a consequence of following a crafted 'story' told through a sequence of spaces. The story, in essence, is the setting in which people interact and engage with various physical aspects of spaces. Based on a particular theme that arises from certain characteristics, the story is narrated by organizing a series of inter-related events on a well-designed stage. The events are triggers that initiate interaction with the physical environment, while the stage refers to the environment of natural and built elements. The experiences of people perceiving the theme, events, stage and the emotions that these evoke can be 
captured in their photographs taken within spaces, but they are so finely woven that they cannot be clearly distinguished from each other due to technical limitations at this stage. Therefore, the captions of photographs that often contain more direct evidence are used to help understand the experiences. The image and the text were grouped together to present a holistic view of the experiences and serve as a source for the recognition of high-frequency words with each word representing an essential aspect of experience. For example, in this case study of Sanlitun, Beijing, the visitor experiences were characterized by over 2,000 high-frequency words filtered from the captions. These words were divided into several categories to clarify the 'theme', 'events', 'stage' and 'emotions' of Sanlitun. The 'theme' was made up of six categories of words reflecting the unique social, cultural and historical characteristics. The 'events' included eighteen categories indicating a variety of daily activities, persons, supplies, related devices and services. The 'stage' was made up of sixteen categories that corresponded to sixteen functional components of the physical environment. The 'emotions' that attempted to evaluate the performance of the 'theme', 'events' and 'stage' had four categories concerning the positive and negative attitudes of visitors. [Table 1 near here] These words, in turn, work together to present what visitors have encountered during their experiences of Sanlitun. Their semantic relationships can then be found by examining the co-occurrences of these words in given captions. For example, the "Beijing" was found to frequently co-occur with "night", "weather" and "China", which not only shows the semantic context of "Beijing" that consists of "night", "weather" and "China" but also depicts a common experience of visiting Beijing that consists of the awareness of the nightscape, natural environment and symbolic meanings of the city.

Based on the division, the photographs were then be categorized according to whether their captions contain the same word, which also means that the photographs 
can be organized into groups according to their subject matter. For example, the photograph shown in Figure 1 was considered as a description of a 'stage', because its caption contains the word "retail" that has been sorted into the category of 'entertainment and shopping' under the heading of 'stage' (see Table 1). [Figure 1 near here] When all the photographs have been grouped into categories representing different aspects of the visitor experience, the main aspects of the experience can then be defined by comparing the sizes of groups.

Once the main aspects have been determined, the 'visualization' can help to identify the most memorable scenes featuring the aspects and to study how the scenes were framed and presented. This analysis is performed based on the identification of the visual content of photographs using a technique called cultural analytics (Manovich, 2007). This includes a set of tools to recognize image features and then cluster groups of images together based on the degree of feature similarity. With this technique a consent is required prior to commencing image data processing, which states that in a given environment a specific subject will have a matching color scheme including a specific range of values on brightness, saturation, hue and RGB color. If a photograph captures the subject, its feature values will then fall within this range, such as the photographs of buildings against the sky sharing a multi-color of light gray, light blue, blue and dark shadows, and the photographs of buildings at night featuring shades of black, dark blue and purple, light orange. [Figure 2 near here] The more photographs a cluster contains, the more typical scene it shows. The researcher can thus study the visual perception of a spatial environment by analyzing and comparing these scenes, as illustrated in the following case studies. 


\section{Case Studies: Sanlitun Village, Beijing and Xintiandi, Shanghai}

The case studies were conducted in two popular shopping, leisure and entertainment destinations in China. The first, Sanlitun Village is located in the center of the Sanlitun - a diplomatic district to the east of downtown Beijing. In the late 1950s, Sanlitun was selected as the location for foreign offices and embassies, thus gradually having a large international community mixed with local residents. New migrants brought different lifestyles including regular visits to bars, cafés and nightclubs, which resulted in an increasing diversity of recreational activities in Beijing. Sanlitun Village opened in 2008 as the first shopping complex in the district. It introduced designer boutiques, branded stores, restaurants, bars and a multiplex cinema that enrich the leisure life of Sanlitun. The development consists of two urban blocks: the Piazza and the Deck with each comprised of several inter-connected buildings, with lanes, courtyards and plazas.

The second case study of Xintiandi is located in the center of downtown Shanghai. It is known for its transformation from a traditional Shanghai community to an entertainment destination in the early 2000s. Based on its well-preserved spatial structure, Xintiandi also covers two urban blocks. The north block is composed of old shikumen buildings - a traditional Shanghainese architecture blending Chinese and Western elements together - with narrow alleys, courtyards and small squares. These old residential buildings were renovated into trendy boutiques, stylish cafés, restaurants, galleries and a museum. The south block is surrounded by a post-modern shopping mall that enhances the site as a unique entertainment destination. For people who have an interest in cosmopolitan Shanghai life, Xintiandi offers a pleasant daytime shopping experience together with a thriving nightlife. 
The first similarity between the two cases is that they are both popular places for leisure activities such as shopping, strolling, meeting and dining. The international brand stores, independent designer boutiques, stylish restaurants and cafés foster an atmosphere that attracts people who desire a fashionable lifestyle. These people consider the places as a place to be and to be seen in the core of the respective city. Their behaviors also nourish the public life between buildings and strengthen the sense of place. The second similarity lies in their spatial patterns. Sanlitun Village is comprised of the Piazza and the Deck, which are connected by two linear streets. Situated adjacent to a main road leading to the downtown area, the Piazza becomes the front entrance of Sanlitun Village while the Deck appears more as a quiet 'backyard' surrounded by narrower streets. Likewise, Xintiandi is comprised of two separate urban blocks. The north block is designed to be the main pedestrian entrance, and the south block is the 'backyard' near an upper-class neighborhood in which all residents are offered a quiet and safe environment. Each of these two places has a dynamic outdoor public realm consisting of paths, portals and places.

Instagram was selected as the primary digital source for the data collection in this project. This is an instant web-based photo-sharing service that enables users to take and immediately upload photographs of everyday life. When people post a photograph on Instagram, they are encouraged to show the geographic location, in order to attract those who are interested to the same place, and also to provide a literal interpretation to express the intention of taking the photograph. All of this is done with people's willingness to speak freely about what they are seeing and feeling, which is extremely important for people-generated image studies.

In this research, over 35,000 sets of social media data for Sanlitun Village and nearly 18,000 sets for Xintiandi including photographs, captions and geographic 
coordinates were downloaded through Instagram's public API. They were generated and shared from July 2013 to July 2014. According to the geographic distribution of the photographs and the pedestrian routes within the sites, both venues are deemed to have a public realm that consists of paths, portals and places. In these two case studies, paths refer to the regular linear spaces, having the lowest density of data points (see SP8-12 and XP6-9 in Figure 2), which are designed for pedestrian movement and have a lengthto-width ratio that is greater than 3:1. Places equate to enclosed regular or irregular spaces with the highest density of data points (see SP1-4 and XP1-2 in Figure 2), which are designed to encourage public social interaction and have a length-to-width ratio of less than 3:1. Portals refer to irregular open spaces with a higher density of data points (see SP5-7 and XP3-5 in Figure 2) and these link the paths with the places thereby serving as the entrance of places and the exit of paths. The photographs taken in SP1, SP3, SP5, SP7, XP1, and XP3 present a visual expression of the photographers' experiences and responses in these spaces and they were grouped together with the related captions and geographic coordinates to analyze how portals and places were used and perceived. [Figure $3 \& 4$ near here]

As discussed previously, places are the stage for moments of experience and portals are the transition points from paths to places that are supposed to give a quick preview of these moments. The photographs taken in Sanlitun Village illustrate this relationship where, for example, SP1 is the central space of the Piazza, an L-shaped square which hosts a wide range of outdoor events including mini concerts, art exhibitions and even cocktail parties (see Figure 2). This square is designed as an outdoor theater with the main audience area situated on a gentle slope at the east end of square facing a large digital screen. There is an additional dry deck fountain located between the auditorium and the digital screen, which also serves as the stage for 
performance. The theater-like space, combined with the surrounding retail stores, restaurants and cafés, gives people opportunities to participate in various activities. The photographs taken at the site, however, provide more information on photographers' attitudes toward the 'theme' expression rather than the quality of the 'events' offered. At first, visitors tend to highlight their experience of SP1 with the names of the location - "Beijing" and "Sanlitun". The co-word cluster analysis indicates that the two words have a stronger connection to emotional concepts including "good", "excellent", "like" and "beautiful". This reflects visitors' positive attitudes toward their experiences associated with these two names, but this does not reveal any factors that have shaped such a positive experience. The image analysis does not yield a definite result either. The photographs of SP1 show almost everything ranging from humans, animals, green vegetation to interior decoration, building facades, food and beverages, and even posters and advertisements, and do not describe a typical scene for this space except for panoramic views of the square. We can thus conclude that SP1 offer a good experience of Beijing and a good experience of Sanlitun, but we can't define what exactly is involved in the experiences. [Figure 5 near here]

The photographs taken in SP3, however, are totally different. SP3 is the central space of the Deck, a sunken plaza surrounded by stylish restaurants, cafés and designer boutiques. This is not a "nuclear square" that can be characterized by a particular building or a vertical structure, instead it is a "dominated square" (Zucker, 1959) created and 'owned' by adjacent buildings as their 'front yard'. The photographs taken in this space express photographers' concerns about the occurrence of events. They tend to consider SP3 as a space for 'doing' something special, such as having brunch, eating an authentic American burger or an Italian pizza, or finding trendy clothes from a boutique shop. Over one-third of their photographs were taken at dining tables and 
almost one-fifth of them were uploaded to express their individual's aesthetic preference for the latest lifestyle and fashion trends.

Compared to these photographs taken with the intention of telling a personal story by magnifying the relevant details of a variety of events, the photographs of SP1 contain a number of images of urban public life. Considering the pedestrian route from SP1 to SP3, the discrepancy between the two groups of photographs indicates a shift in the role of photographers, from an observer of a new and unfamiliar environment to a participant who has adapted to the environment. We can thus characterize a typical behavioral pattern such as when moving into a new place, people often seek to increase the awareness of 'where am I' by recognizing features that can help them to make a distinction. They therefore capture the features and tag them using the name of the place, not only to remind themselves but also to remind other followers of 'where am I'. As revealed by the text analysis, people tend to name the photographs of SP1 with "Beijing", which means that in their eyes this square is 'the square of Beijing' and these panoramic photographs were taken to help record and share their first-hand impressions of SP1 as a part of Beijing. After moving into SP3, however, they name more photographs of their favorite moments with "Sanlitun". This clearly shows their intention to establish emotional connections with the space based on their growing awareness of "Sanlitun" as a specific independent site. This change in naming behavior, to some extent, supports the model of human perception of the environment, which consists of the evaluation of information received about the physical aspects and the interpretation of information related to the interpreter.

As the 'portals' to these two different kinds of 'places', SP5 and SP7 offer different preview experiences. SP5 is the 'doorway' to SP1. It is designed as an independent semi-enclosed irregular square formed by two sets of buildings at right 
angles to each other, opening onto the city streets and thus providing easy viewing and access from outside. The buildings are designed in the same style as those surrounding SP1, establishing a close visual correlation between two spaces. The square is often animated with temporary sculptures or installations to attract visitors and encourage longer stays, which to some extent improves the functional relationship between SP5 and SP1. Therefore, when people begin moving through SP5, they know nothing about SP1 but they probably have an expectation having interacted with SP5, and thus they have the same perceptual experiences that many others appear to have had in SP1. The data analysis reveals that most visitors perceive SP5 as a space for 'theme' expression, and the two themes - "Beijing" and "Sanlitun" - are tightly connected to emotional concepts such as "excellent" and "good", similar to SP1. Additionally, when they are in the semi-enclosed square, they appear more concerned about natural factors influencing the quality of the outdoor experience, such as "weather", "morning" and "night". As a result, if SP1 as an open square is designed to be a public 'room' of the city of Beijing, then SP5 as the 'doorway' of the 'room' not only provides a sample of how to experience SP1 but also protects SP1 from outside influences. [Figure 6 near here]

Unlike SP5 that offers an experience of passing through a 'doorway', SP7 acts like a 'showroom' providing the first glimpse of SP3. It is not a square but an incidental open space formed by the setbacks of the surrounding buildings, which look monotonous but display the most important part of SP3 consisting of a set of sculptural buildings with a sunken space between them. This space is where visitors are going to get their first impression of SP3 and informs themselves of 'where am I', and the moments that it provides would appear worthy of being captured and shared with others. However, the data analysis reveals that only 2.4 per cent of photographs were taken in this space, reflecting an absence of interest to visitors. The discrepancy is probably due 
to a mismatch between what is expected to happen and what actually happens in SP7. As discussed above, SP3 has been perceived as a space for participation, in which visitors are strongly encouraged to attend a variety of commercial and recreational activities and to thus establish an emotional connection. SP7 as a portal space of SP3 should provide opportunities for sufficient rehearsals and preparation, enabling new visitors to respond quickly to the events occurring in SP3, as SP5 does now. This space does not, however, give any indication for this except for a panoramic view of the main perimeter buildings.

In contrast to SP7, XP3 as the main entrance to the North Block of Xintiandi, serves as a good example of how to create a portal of a place for participation. The key to this is being a real 'place' with a strong sense of place. It is designed to be more of a street destination surrounded by outdoor cafes and restaurants, where people are given opportunities and the facilities to take part in a variety of 'events'. They share their experiences gained from these events on Instagram by using a group of related words such as "eat", "drink", "tea", "day" and "week" and plenty of photographs showing smiling faces, food and beverages. On one hand, their enthusiastic responses to what is being offered in XP3 attract potential visitors to come and stay with them, on the other hand, however, they may be motivated by others' behaviors and attitudes toward what will be offered in subsequent experiences and this increases their desire for it. These active participators make XP3 an effective information carrier that is capable of telling new visitors about the whole site. However, it is worth noting that XP3 does not connect directly to XP1 - the central 'place' of the North Block where most outdoor social activities take place - but joins via a linear path between them. The two kinds of place can thus be clearly distinguished from one another, and the high contrast between a 
narrow, short and restrictive 'preview' and a large, stable and generous 'climax' can be maintained. [Figure 7 near here]

In summary, the 'place-type' portal will provide significant benefit in connection with places for participation as it is an interactive space where a series of inter-related events occur. Visitors can thus start to learn "what to do" and "how to do" by participating in these events and eventually become active participators who are able to quickly build emotional connection with their surroundings. When however, they start moving toward another kind of place that has a particular thematic expression, they tend to be passive participators who seek to recognize and understand the substantive characteristics of the theme. This calls for a striking focal point to be established in the portal to help them start this process. For example, the shining glass facades of SP5 attract the crowd's attention through many bright, rich-colored panels, at the same time, the colorful lights reflected from the glass surfaces also give a visual indication of the vibrant, dynamic scenes that are unfolding in the SP1. Both the 'doorway' and 'showroom' have at least one focal point, but they differ in the types of activities available. The 'doorway' allows active participation and involvement to coexist with the passive receiving of information, thereby encouraging visitors to actively collect information and get involved in the space. The 'showroom', however, does not provide visitors with the same opportunities for information collection.

\section{Conclusion}

To promote a better understanding of portals - transition spaces providing a gateway from path to place - within the urban environment, this paper presents an extended discussion of their form as an interactive preview of adjacent places. Based on a comparative analysis of ordinary people's experiences in different portal and place 
spaces, there are three types of portal identified, including the 'doorway', the 'showroom', and the 'place'. For urban designers and place-makers, deciding which of these three types is the most appropriate depends on the form of the adjacent destination place. The first two types can both be essential parts of place of expression, while the third type is a place of participation. These findings complement to White's (1999) research study of portals and further extend the understanding of these important physical urban entities.

This research was facilitated by the use of people-generated image analysis in order to investigate people's actual feelings and attitudes toward the quality of the physical environment. Nearly 53,000 Instagram photographs were downloaded for this study with an intention to obtain more precise results. It is important to note, however, that there are still inconsistencies and inaccuracies in the data analysis process due to the manner in which some users have uploaded images and recorded their views on Instagram. Firstly, although Instagram users are allowed to take photographs and immediately share them with others, in fact, the users typically undertake a conscious selection process of which images to upload. Researchers are clearly not privileged to this information and therefore cannot understand the extent to which this behavior obstructs the investigation of how people truly experience the urban environment. Secondly, the data analytical framework was constructed based on the one-to-one correspondence between the caption and the image, which overlooks the possibility that some images were uploaded with indefinite or irrelevant captions. They could therefore have been grouped into the wrong categories thereby making the image analysis somewhat harder. These limitations mean that the Instagram images collected for this research cannot fully explain the experience of people, thus requiring some integration with other traditional research instruments such as observations, questionnaires and 
interviews. Nevertheless, these images do give us a greater insight into the way that people use and experience of our cities. This project therefore marks a significant point in enabling researchers of urban environments and subsequently urban designers to better understand the impact of the public realm upon the users of our towns and cities in terms of perception and use.

References:

Ahern, S., Naaman, M., Nair, R., and Yang, J.H.I. (2007) World Explorer: Visualizing Aggregate Data From Unstructured Text in Geo-referenced Collections. Proceedings of the 7th ACM/IEEE-CS Joint Conference on Digital Libraries, JCDL'07 Joint Conference on Digital Libraries, Vancouver, June 2007. New York: ACM. doi:10.1145/1255175.1255177

Ciuccarelli, P., Lupi, G., and Simeone, L. (2014) Visualizing the Data City: Social Media as a Source of Knowledge for Urban Planning and Management. Heidelberg: Springer. doi: 10.1007/978-3-319-02195-9

Crandall, D. J., Backstrom, L., Huttenlocher, D., and Kleinberg, J. (2009). Mapping the World's Photos. Proceedings of the 18th International Conference on World Wide Web, WWW'09 The 18th International World Wide Web Conference, Madrid, April 2009. New York: ACM. doi: 10.1145/1526709.1526812

Cranshaw, J., Schwartz, R., Hong, J.I., and Sadeh, N. (2012) The Livehoods Project: Utilizing Social Media to Understand the Dynamics of a City. Proceedings of the 6th International AAAI Conference on Weblogs and Social Media, The 6th International AAAI Conference on Weblogs and Social Media, Dublin, June 2012. Palo Alto: The AAAI Press.

Deng, D. P., Chuang, T. R., and Lemmens, R. (2009). Conceptualization of Place via Spatial Clustering and Co-occurrence Analysis. Proceedings of the 2009 International Workshop on Location Based Social Networks, GIS'09 17th SIGSPATIAL International Conference on Advances in Geographic Information Systems, Seattle, November 2009. New York: ACM. doi: $10.1145 / 1629890.1629902$

Dorwart, C. E., Moore, R. L., and Leung, Y. F. (2009). Visitors' Perceptions of a Trail Environment and Effects on Experiences: A Model for Nature-based Recreation 
Experiences. Leisure Sciences: An Interdisciplinary Journal, 32(1), 33-54. doi: https://doi.org/10.1080/01490400903430863

Encalada, L., Portugal, I.B., Ferreira, C.C., and Rocha, J. (2017). Identifying Tourist Places of Interest Based on Digital Imprints: Towards a Sustainable Smart City. Sustainability, 9(12), 1-19. doi: https://doi.org/10.3390/su9122317

Garrod, B. (2007). A Snapshot into the Past: The Utility of Volunteer-employed Photography Techniques in Planning and Managing Heritage Tourism. Journal of Heritage Tourism, 2(1), 14-35. doi: https://doi.org/10.2167/jht018.0

Guerrero, P., Steen, M.M., Stahl, O.A., Bernhard, S. (2016). Revealing Cultural Ecosystem Services through Instagram Images: The Potential of Social Media Volunteered Geographic Information for Urban Green Infrastructure Planning and Governance. Urban Planning, 1(2), 1-17. doi: http://dx.doi.org/10.17645/up.v1i2.609

Hochman, N., and Schwartz, R. (2012). Visualizing Instagram: Tracing Cultural Visual Rhythms. Proceedings of the Workshop on Social Media Visualization in conjunction with the 6th International AAAI Conference on Weblogs and Social Media, The 6th International AAAI Conference on Weblogs and Social Media, Dublin, June 2012. Palo Alto: The AAAI Press.

Hochman, N., and Manovich, L. (2013). Zooming into an Instagram City: Reading the local through social media. First Monday, 18(7). doi: https://doi.org/10.5210/fm.v18i7.4711

Jacobsen, J. K. S. (2007). Use of Landscape Perception Methods in Tourism Studies: A Review of Photo-based Research Approaches. Tourism Geographies,9(3), 234253. doi: https://doi.org/10.1080/14616680701422871

Kennedy, L., Naaman, M., Ahern, S., Nair, R., and Rattenbury, T. (2007). How Flickr Helps Us Make Sense of the World: Context and Content in Communitycontributed Media Collections. Proceedings of the 15th international conference on Multimedia, MM'07 The 15th ACM International Conference on Multimedia, Augsburg, September 2007.New York: ACM. doi: $10.1145 / 1291233.1291384$

Lynch, K. (1960). The Image of the City. Cambridge: Mit Press.

Mackay, K. J., and Couldwell, C. M. (2004). Using Visitor-employed Photography to Investigate Destination Image. Journal of Travel Research, 42(4), 390-396. doi: https://doi.org/10.1177/0047287504263035 
Manovich, L. (2007). Cultural Analytics: White Paper. Retrieved from http://softwarestudies.com/cultural_analytics/cultural_analytics_2008.doc Moughtin, J. C. (1992). Urban Design: Street and Square. Oxford: Butterworth. Psyllidis, A., Bozzon, A., Bocconi, S., and Bolivar, C.T. (2015). A Platform for Urban Analytics and Semantic Data Integration in City Planning. In Celani, G., Speriling, D.M., and Franco, J.M.S. (Eds.), Computer-Aided Architectural Design Futures: The Next City-New Technologies and the Future of the Built Environment, The 16th International Conference CAAD Futures 2015, Sao Paulo, July 2015. Heidelberg: Springer.

Schwartz, R. and Hochman, N. (2014). The Social Media Life of Public Spaces: Reading Places Through the Lens of Geo-Tagged Data. In Wilken, R., and Goggin, G.(Eds.), Locative Media. New York: Routledge. doi:

Sigurbjörnsson, B., and Van Zwol, R. (2008). Flickr Tag Recommendation Based on Collective Knowledge. Proceedings of the 17th International Conference on World Wide Web, WWW08 The 17th International World Wide Web Conference, Beijing, April 2008. New York: ACM. doi: $10.1145 / 1367497.1367542$

Tibbalds, F. (1992). Making People-friendly Towns: Improving the Public Environment in Towns and Cities. London: Spon Press.

Ushizima, D., Manovich, L., Margolis, T., and Douglass, J. (2012). Cultural Analytics of Large Datasets from Flickr. Proceedings of the workshop on Social Media Visualization (SocMedVis) in conjunction with the 6th International AAAI Conference on Weblogs and Social Media, The 6th International AAAI Conference on Weblogs and Social Media, Dublin, June 2012. Palo Alto: The AAAI Press.

White, E. T. (1999). Path Portal Place: Appreciating Public Space in Urban Environments. Florida: Architectural Media.

Xia, C.L., Schwartz, R., Xie, K., Krebs, A., Langdon, A., Ting, J. and Naaman, M. (2014). CityBeat: Real-time Social Media Visualization of Hyper-local City Data. Proceedings of the 23rd International Conference on World Wide Web, WWW'14 23rd International World Wide Web Conference, Seoul, April 2014. New York: ACM. doi: 10.1145/2567948.2577020

Zhou, B., Liu, L., Oliva, A., and Torralba, A. (2014). Recognizing City Identity via Attribute Analysis of Geo-tagged Images. In Fleet D., Pajdla T., Schiele B., 
Tuytelaars T. (Eds.), Computer Vision - ECCV 2014. Cham: Springer. doi: https://doi.org/10.1007/978-3-319-10578-9_34

Zucker, P. (1959). Town and Square: From the Agora to the Village Green. New York: Columbia University Press. 


\section{Examining Three Roles of Urban 'Portals' in their Relationship with}

\section{'Places' using Social Media Photographs}

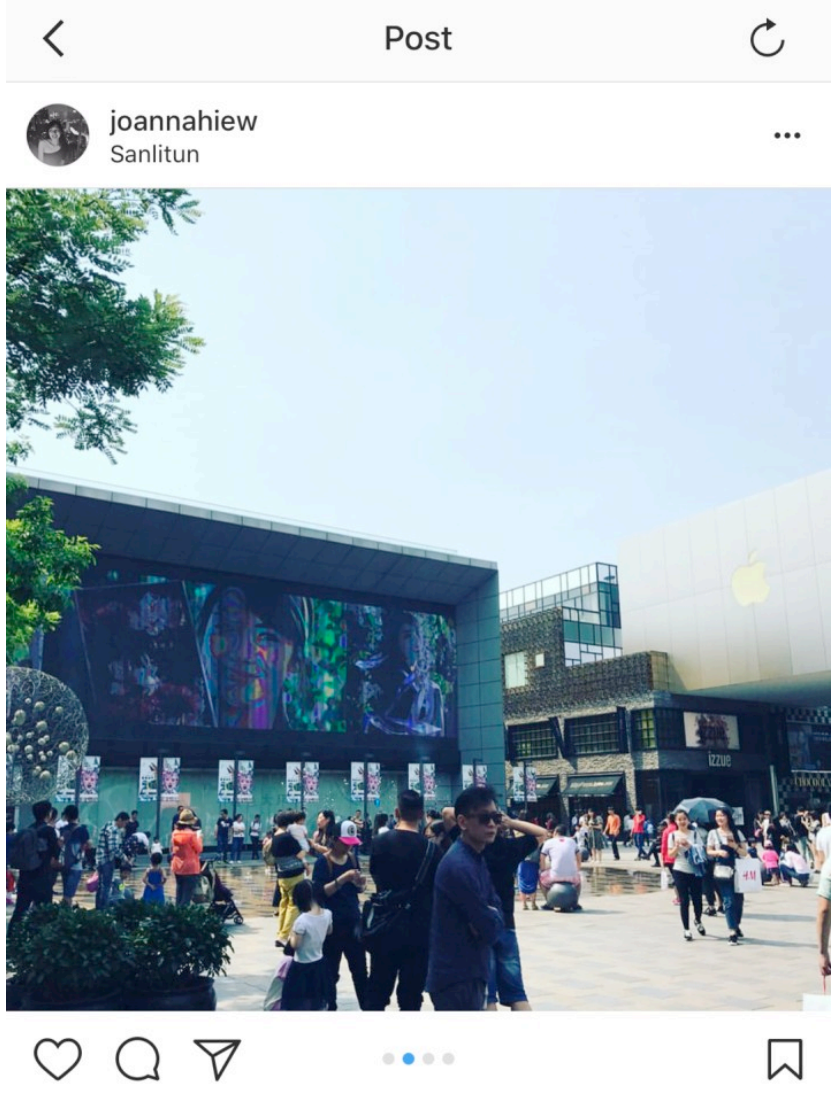

23 likes

joannahiew Human scale retail destination

\#lifeasanarchitect \#beijingbest \#retaildesign

View all 4 comments

Figure 1: An Instagram photograph of Sanlitun Village, Beijing (joannahiew, 2017)

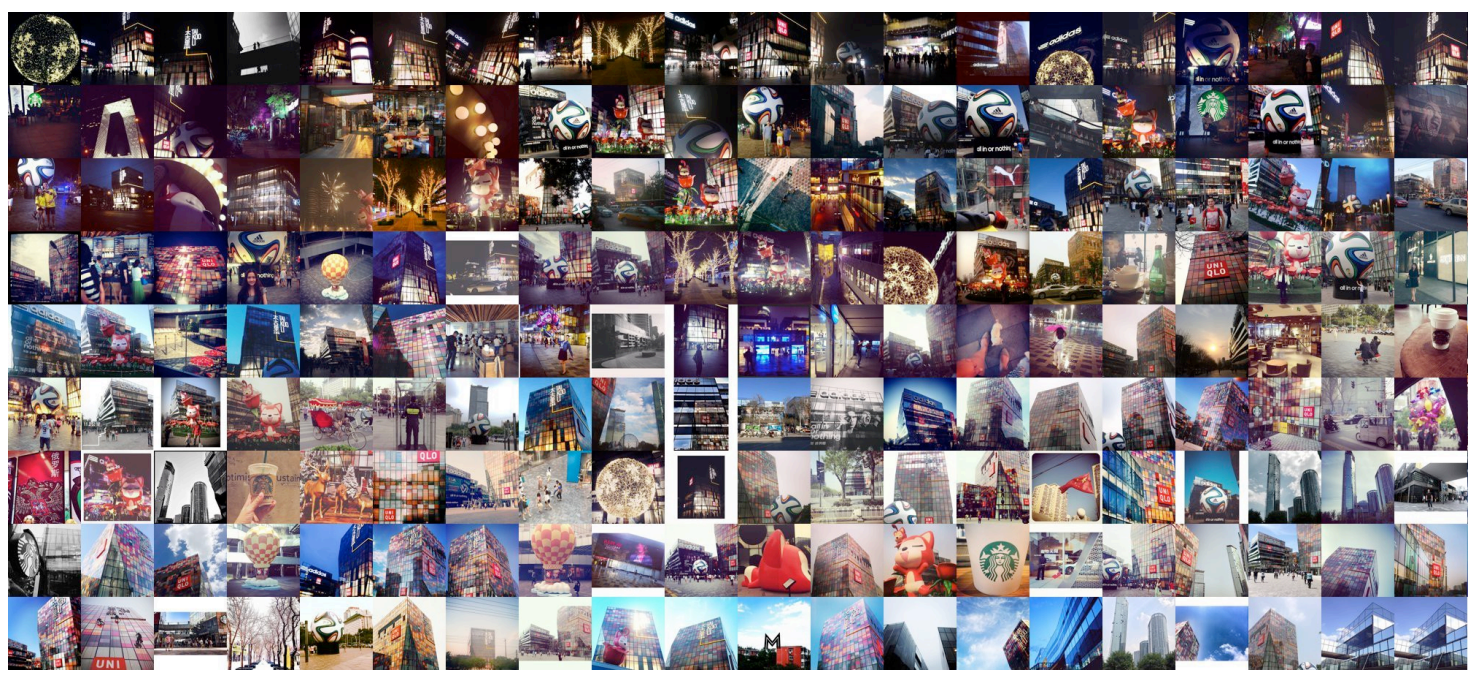


Figure 2: The visualization of the photographs of buildings in Sanlitun Village, Beijing.

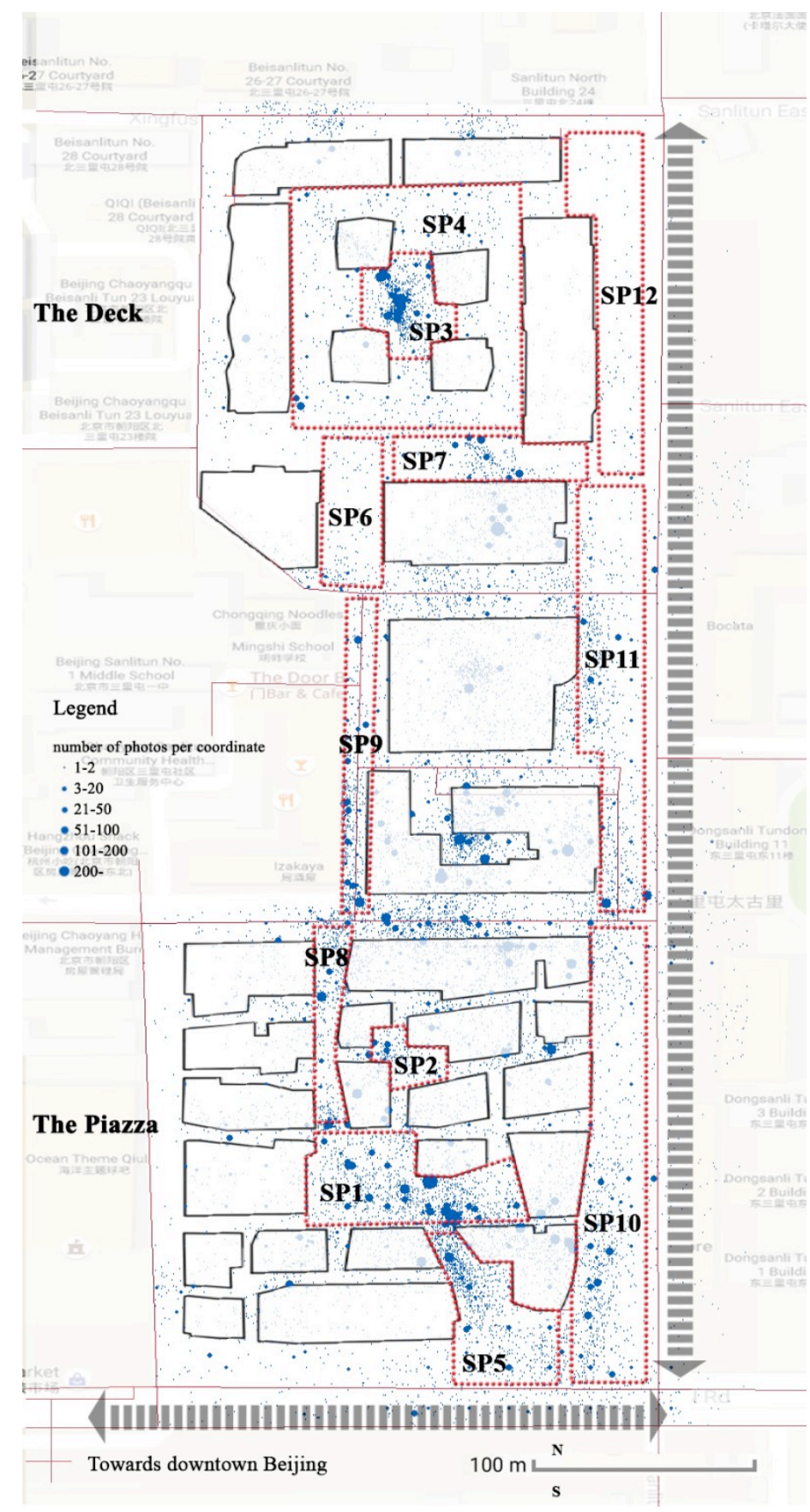

Figure 3: The spatial structure of Sanlitun Village, Beijing. 


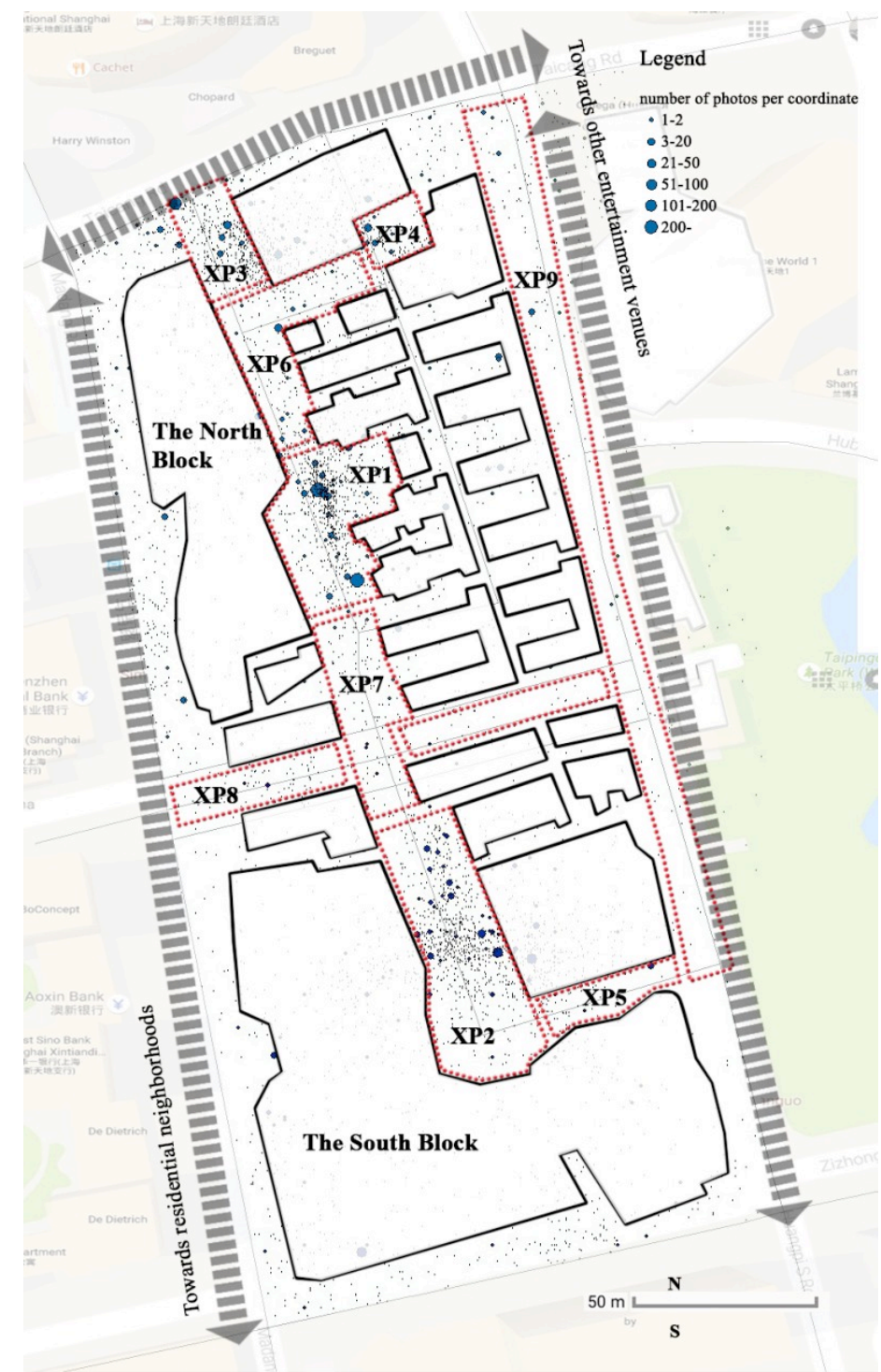

Figure 4: The spatial structure of Xintiandi, Shanghai.
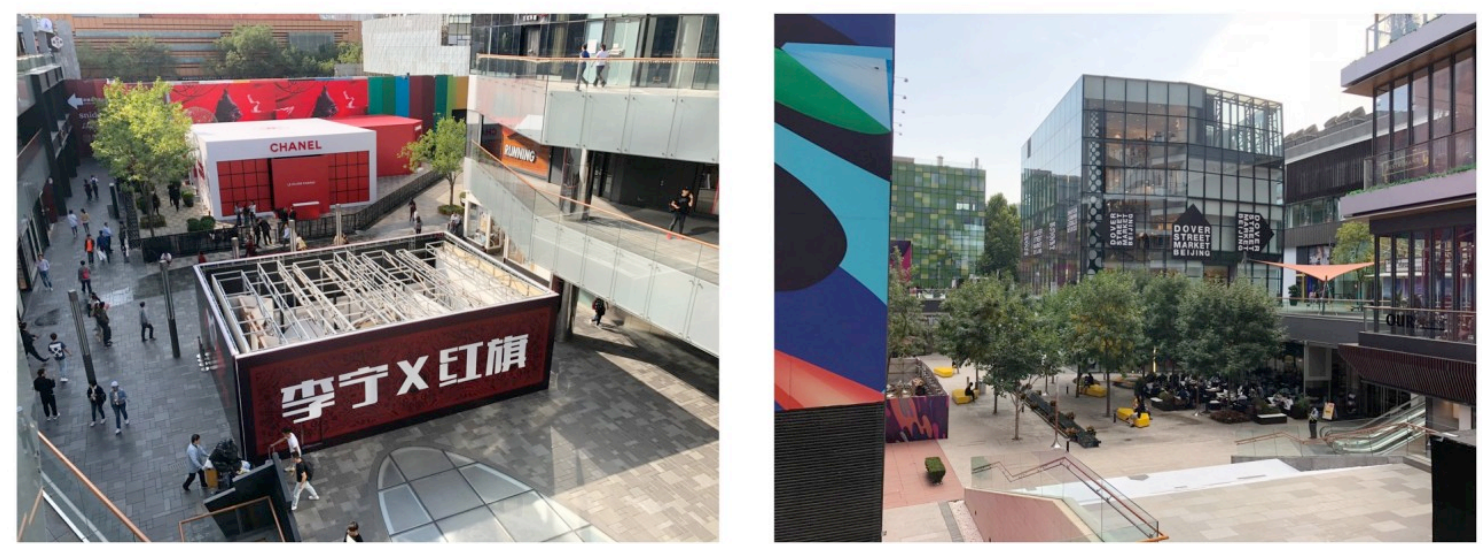

Figure 5: SP1 (left) and SP3 (right) in Sanlitun Village, Beijing. 

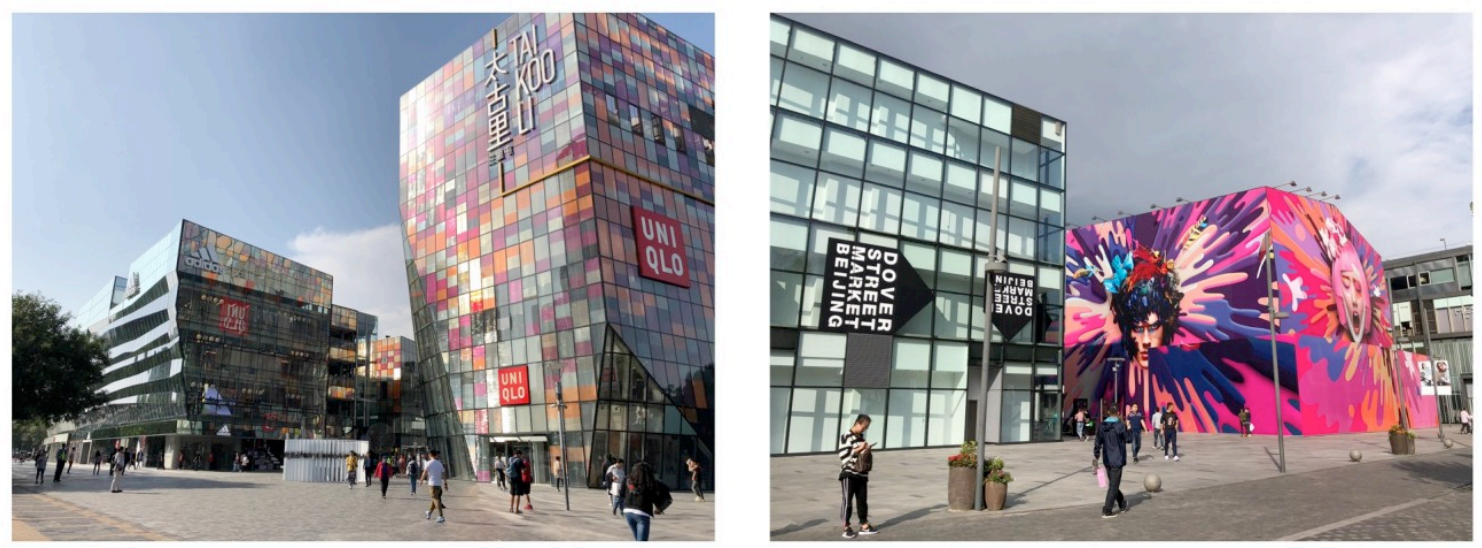

Figure 6: SP5 (left) and SP7 (right) in Sanlitun Village, Beijing.

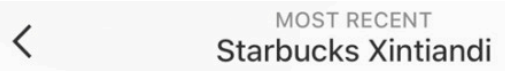

16 chulheepark · Follow

Starbucks Xintiandi

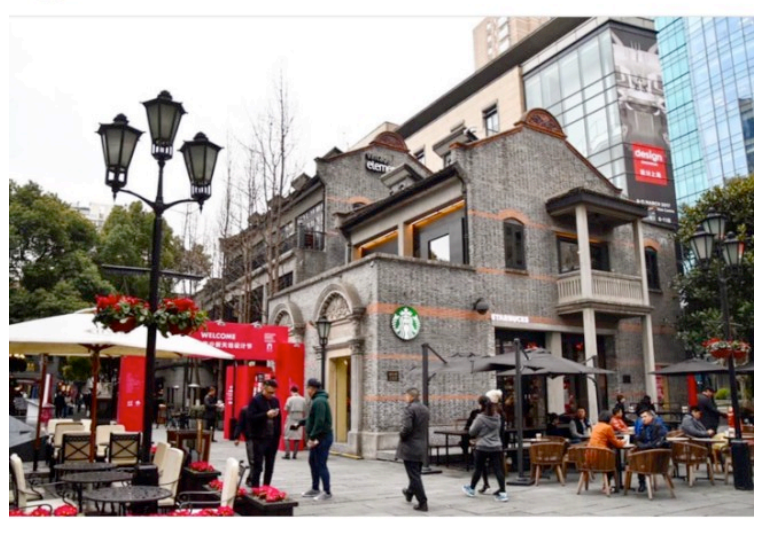

$\circ \subset \nabla$

ఐ

50 likes

chulheepark 2017.03.16 \#상해 (\#shanghai / \#上海) 여행 4일 차 - 여전히 멋있는 \#신천지 (\#新天地) \#스타벅스 (\#starbucks / \#星巴克 ) 도착 참새가 방앗간을 그냥 지나칠 수 없지 ㅎ... more

View all 5 comments

Figure 7: An Instagram photograph of XP3 in Xintiandi Shanghai (chulheepark, 2017). 
Permissions from joannahiew and chulheepark are shown below (my Instagram ID is joomoly)

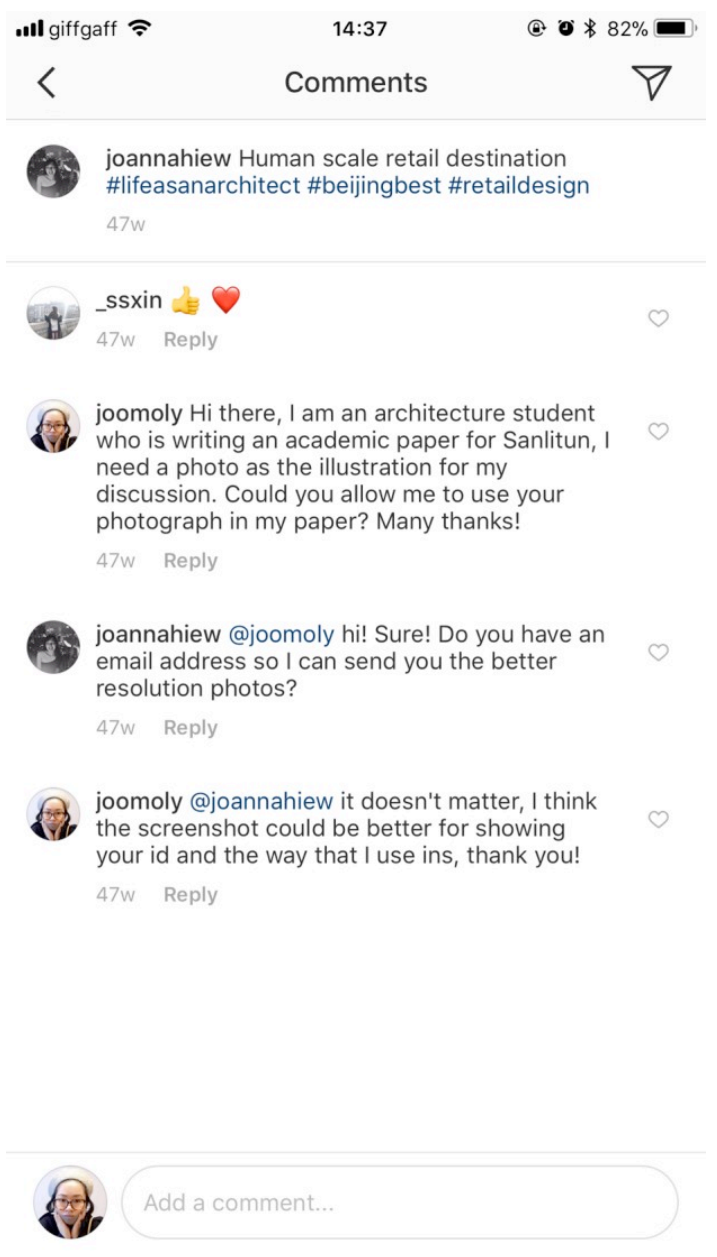

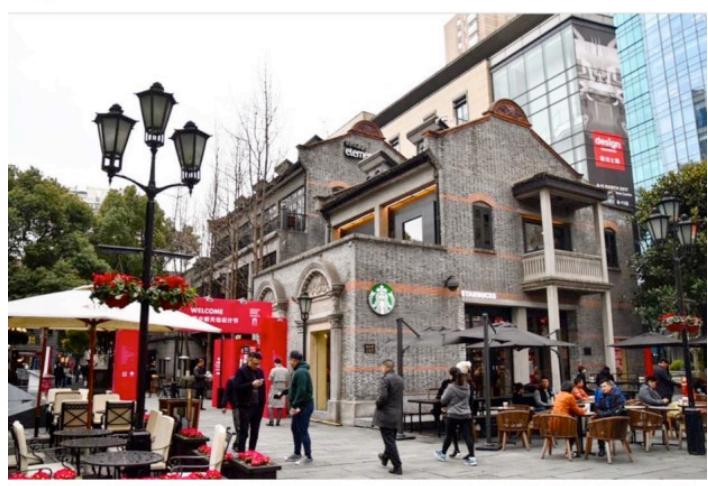

$\bigcirc \bigcirc \nabla$

50 likes

chulheepark 2017.03.16 \#상해 ( \#shanghai / \#上海) 여행 4일 차 - 여전히 멋있는 \#신천지 ( \#新天地 ) \#스타벅스 ( \#starbucks / \#星巴克 ) 도착 참새가 방앗간을 그냥 지나칠 수 없지 ㅎ... more

View all 5 comments

joomoly $\mathrm{Hi}$ there, I am an architecture student who is writing an academic paper for Sanlitun, I need a photo as the illustration for my discussion. Could you allow me to use your photograph in my paper? Many thanks! chulheepark @joomoly sure! Why not? 2017年3月16日· SEE TRANSLATION

N18 lisichka_nastia - Follow
$\widehat{\Omega}$
Q
+ $0 \stackrel{\circ}{\circ}$ 